\title{
LOLLO, María Soledad, Diarios de Viaje por América. Un instrumento del reformismo borbónico en el Río de la Plata, Universidad de Huelva Publicaciones, Huelva, 2010, 172 páginas
}

El impulso exploratorio iniciado en 1492 encuentra su apogeo, esplendor y consumación en el marco del proyecto ilustrado del siglo XVIII; un siglo en el que se consolida la instalación efectiva de un mercado mundial que impone los mecanismos de su propia expansión a través de la producción de bienes y símbolos. Las expediciones científicas estaban promovidas por las Monarquías de Inglaterra, Francia y España que confiando en la ciencia y sus prácticas habían encontrado el mejor discurso de legitimación a las acciones de dominio político y económico. Este trabajo se concentra en el proceso reformista que involucró a la Monarquía Borbónica y a los territorios americanos. Preocupada por redefinir los contornos de su poder jurisdiccional y relanzar su economía, la creación de las expediciones científicas implicó una intervención territorial y jurisdiccional que se fundó en la apelación, real y simbólica, a la ciencia.

En el primer capítulo Los Diarios de viaje y los viajeros, se efectúa un análisis pormenorizado de qué significado tienen los desplazamientos, cómo se configura la imagen del viajero, qué sucede cuando fruto de ese viaje se elige una transmisión en la escritura, qué inscripción se hace de los destinatarios y cómo la lógica del viaje es en definitiva un suceso hacia la alteridad. Los relatos de viajeros han capturado el interés crítico de los historiadores en diversos siglos y han provocado profundas discusiones que, en última instancia, constituyen el testimonio fehaciente de su propia relevancia cultural. Es durante los últimos años que la producción organizada desde las ciencias sociales se ha concentrado en un análisis más complejo y transdisciplinar sobre los relatos de viajeros y en esta tarea se ha accedido a una acumulación de conocimiento que permite observar estos objetos de estudio desde una perspectiva que incide en cómo se construye el relato de viaje como entidad cultural, pero esencialmente en los mecanismos desde los cuales ese relato concibe al espacio, legitima el tiempo y organiza la imagen del otro, de lo otro en una dialéctica constante, producto fundamentalmente del proceso especular y pendular de lo narrado, la narración y el narrador. Todas estas argumentaciones, la autora, las lleva adelante a través de los últimos aportes de la historiografía, la antropología y la crítica cultural. Es de destacar, por una parte, la elección del género de "diario de viaje" para el período trabajado en el que claramente se produce una identificación entre el autor/narrador y viajero como aquel que ordena los signos del texto así como ordena el diario vivir en el viaje. Pero a su vez, la interpretación que de este escrito hicieron los funcionarios del reformismo. Por otra parte, el haberse tenido, especialmente en cuenta los trabajos de los antropólogos, geógrafos e historiadores españoles contemporáneos como Juan Pimentel, Manuel Lucena Giraldo y Carlos Martínez Shaw. 
El segundo capítulo, El Río de la Plata en los Diarios de Viaje desde "el hambre” hasta "la abundancia", se describe cómo el espacio rioplatense fue visto por los viajeros. Toda la argumentación se sostiene a partir del concepto de frontera. La polisemia del mismo hace que la autora tome como estrategia el análisis de una doble frontera, de manera tal que "Viajeros e ilustrados constataron la presencia de las fronteras. Los viajeros perfectos lo hicieron a través de una óptica europea pero situados en una zona de contacto...." Los Ilustrados-viajeros imperfectos-en cambio, percibieron las fronteras desde la Metrópoli y a partir de la lectura de los diarios de viaje. La principal diferencia entre unos y otros radica en que los primeros, por su contacto empírico con el continente americano, pudieron advertir con más facilidad que los segundos la dinámica interna de las colonias" (pág.80). Y en esta línea de tratamiento se muestra cómo el espacio rioplatense se conformó en un espacio de frontera en el que diferentes grupos inter-actuaban en busca de consolidar su poder sobre el mismo. Pero, también, como un espacio de frontera asediado por la amenaza extranjera.

Asimismo, el trabajo explora cómo y por que los diarios de viaje fungían de instrumentos del reformismo. En la deseada regeneración que detuviera el declive de la corona (el tema por excelencia del siglo XVIII de España) participan los vínculos más estrechos de los territorios de América y la más amplia explotación de sus recursos fiscales, políticos y naturales. Dentro de este contexto de reforma política y social, el programa de expediciones científicas a América promovidas por la corona de los años 1760 en adelante fue el signo más claro de la dinámica de la Ilustración de la ciencia española. Los territorios de América podrían ser recuperados, y su rentabilidad podría aumentar a ciento por ciento.

Finalmente el capítulo tercero "Desde "Noticias Secretas" hasta "El Lazarillo de Ciegos Caminantes" se examinan los escritos de José del Campillo y Cosio, referente de la primera etapa del reformismo borbónico y Pedro Rodriguez Campomanes, quien ocupó diversos puestos en la administración borbónica hasta llegar a justificar y legitimar las reformas que debían implementarse. La autora pone en tensión los escritos de estos funcionarios con los diarios de viaje. Tanto Noticias Secretas de América de Jorge Juan y Antonio de Ulloa como el Lazarillo de Ciegos Caminantes de Concolocorvo son diarios de viaje profusamente trabajados pero la novedad de la lectura que se propone está dada por señalar la analogía que se establece entre el viaje, lo visto y el conocimiento como un tópico común de la época. Esta analogía muestra que para los hombres del siglo XVIII, ser viajero era ser poco confiable, y la tarea era vista como una actividad similar a los poetas, actores, ladrones, mentirosos. Cuando los viajeros se arman con los métodos y prácticas de la ciencia moderna comenzaron a ser percibidos como personas fiables, pero esa creencia necesitaba ser sostenida. Estos "testigos imparciales del mundo" recurrían a todas las estrategias retórico/discursivas que facilitaran la transmisión de lo leído en el libro de la "Naturaleza" pero fundamentalmente son los funcionarios de la administración borbónica quienes insertaron ese relato en las necesidades de reforma de las colonias. En definitiva, Lollo destaca la capacidad de la escritura de viaje para que se evidencien las dimensiones "objetivas" y "subjetivas", es decir los aspectos literarios y científicos. Es en este punto 
de intercambio conflictivo entre lo científico, lo político y la experiencia singular, desde donde propone interrogar a los relatos de viaje con el objeto de acercarse a su contexto y a su significado histórico y cultural.

La cuidada edición y los anexos cartográficos se aúnan al estudio detallado y lúcido de María Soledad Lollo constituyendo un valioso aporte a los estudios de literatura de viaje en general y de este tópico en el reformismo borbónico.

Fernando Navarro CESOR-CIEHUM/UNR 